\title{
POLÍTICAS E GESTÃO DA EDUCAÇÃO BÁSICA EM CONTEXTOS IBEROAMERICANOS
}

\author{
POLÍTICAS Y GESTIÓN DE LA EDUCACIÓN BÁSICA EN CONTEXTOS \\ IBEROAMERICANOS
}

\author{
POLICIES AND MANAGEMENT OF BASIC EDUCATION IN IBERO-AMERICAN \\ CONTEXTS
}

Arlete Ramos dos SANTOS ${ }^{1}$

Mara Lúcia RAMALHO ${ }^{2}$

Washington Cesar Shoiti NOZU ${ }^{3}$

As políticas educacionais fazem parte de um processo marcado pela diversidade, complexidade, disputa e combinações sobre os mecanismos e estratégias dos diversos interesses dos sujeitos e dos grupos envolvidos. Nesse sentido, a implementação das políticas educacionais nos sistemas de ensino e, principalmente, nas escolas, deve ser compreendida como uma dinâmica que revela e constrói trajetórias, conformando um diálogo entre temporalidades, subjetividades e territorialidades, de modo que se traduz numa dimensão histórica, coletiva e social nos diferentes contextos.

Para Ball (1987), há uma dimensão subjetiva nesse processo que está direcionada para a forma como os sujeitos operam as políticas na dimensão institucional, na qual acontecem as decisões, as reuniões, os recursos orçamentários, os conteúdos simbólicos, os comportamentos e as atitudes dos atores individuais, grupais e institucionais associados à política, e entre tantas outras variáveis, as ações interpretativas e as discricionárias, que definirão como esse processo ocorrerá (OLIVEIRA, 2019).

Estes aspectos estão evidenciados, principalmente, em políticas e práticas que se concretizam nos sistemas de ensino e no cotidiano escolar, mas que está presente nos

${ }^{1}$ Universidade Estadual do Sudoeste da Bahia (UESB), Vitória da Conquista - BA - Brasil. Professora Titular, Docente Permanente do Programa de Pós-Graduação em Educação (UESB) e Docente do Programa de PósGraduação em Educação (UESC). Doutorado em Educação (UFMG). ORCID: https://orcid.org/0000-00030217-3805. E-mail: arlerp@hotmail.com

${ }^{2}$ Universidade Federal dos Vales do Jequitinhonha e Mucuri (UFVJM), Diamantina - MG - Brasil. Professora Adjunta e Docente Permanente do Programa de Pós-Graduação em Educação (Mestrado Profissional). Doutorado em Educação (PUC/MG). ORCID: https://orcid.org/0000-0002-8314-4688. E-mail: mararamalho03@yahoo.com.br

${ }^{3}$ Universidade Federal da Grande Dourados - (UFGD), Dourados - MS - Brasil. Professor Adjunto, Docente Permanente do Programa de Pós-Graduação em Educação e do Programa de Pós-Graduação em Fronteiras e Direitos Humanos. Doutorado em Educação (UFGD). ORCID: https://orcid.org/0000-0003-1942-0390. E-mail: wcsn1984@yahoo.com.br 
elementos subjacentes à Nova Gestão Pública, por meio de reformas educacionais que alteram as atribuições e a autonomia da gestão escolar, ocasionando a descentralização administrativa, pedagógica e a accountability. Essas reformas refletem diretamente no planejamento escolar, de modo que os agentes educacionais precisam repensar a própria prática no seu contexto, para dar conta da implementação de uma nova política educacional que se conforma ao projeto histórico de sociedade pensado pelas grandes agências do capitalismo global.

Desde a segunda metade dos anos de 1990 tem ocorrido uma "repolitização" da política, considerando o destaque que ganharam alguns fenômenos sociais, dentre eles, segundo Neves (2005): a nova cidadania; a nova participação social; a noção de voluntariado; a sociedade civil ativa; a ideia do deslocamento do "conflito" para a "colaboração social" e o modelo gerencial de governança.

Nesse contexto, os governos e as organizações da sociedade civil começaram a perceber a necessidade de uma intervenção comum, que contemplasse a atuação de ambas as instituições. Por tal interesse, passaram a defender um só projeto, com três importantes linhas de atuação, que ganhou o nome de Movimento Todos pela Educação-MTE.

Este projeto, na perspectiva de Giddens (2001), teve como pilares as seguintes ações: a primeira foi destinada a redefinir o sentido da organização e participação historicamente construída por trabalhadores; a segunda, dirigida à necessidade de pacificar e/ou refuncionalizar as organizações dos trabalhadores identificados historicamente como luta pela ampliação de direitos sociais; e a terceira e última referiu-se ao estímulo e fortalecimento à proliferação de grupos de interesses motivados por bandeiras e demandas que não conflitam com a lógica central do sistema capitalista.

Como toda causa provoca um determinado efeito, segundo Martins (2007), este triplo movimento desencadeou na sociedade daquele contexto algumas consequências relacionadas à dificuldade para a compreensão crítica das relações sociais capitalistas, a diminuição das resistências e protestos contra a dinâmica capitalista, e o incentivo ao pluralismo sem identidade de classe, bem como a redução de uma classe burguesa e o surgimento de "uma direita para o social", ou seja, um amplo agrupamento de empresários que passam a levantar a bandeira em prol ao fortalecimento da intervenção das empresas na organização das políticas educacionais.

Após ampla divulgação internacional do movimento Todos pela Educação, mediante a exposição nas conferências ocorridas na Tailândia (1990), no Senegal (2000) e durante os eventos coordenados pela Unesco e o Banco Mundial, o referido grupo, já organizado no 
Brasil, constituiu a sua identidade em dois contextos temporais distintos, por meio do desenvolvimento de três movimentos, a seguir mencionados.

O primeiro refere-se ao movimento Todos pela Educação, que teve uma configuração apartidária e plural. Congregou representantes de diferentes setores da sociedade, como gestores públicos, educadores, pais, alunos, pesquisadores, profissionais de imprensa, empresários e todas as pessoas ou organizações sociais que contaram com o apoio de líderes empresariais, cujas constatações se materializam por meio de um projeto elaborado para impulsionar as ações. Na busca de afirmação para o referido projeto e ampla divulgação no cenário internacional, o mesmo foi apresentado no Congresso Ações de Responsabilidade Social em Educação: melhores práticas na América Latina.

Neste evento, que deu o Todos pela Educação ganha ampla divulgação, organizado por três empresas, a saber: a Fundação Coleman, a Fundação Jacobs e o Instituto Gerdau, nasceu a indicação de construção de um pacto nacional em defesa da educação básica, cuja sustentabilidade financeira a princípio teve os pilares pautados na captação de recursos privados, por meio de recursos advindos de patrocínio das empresas, Grupo Gerdau, Grupo Suzano, Banco Itaú, Banco Bradesco e Organizações Globo.

Este pacto teve como ponto de partida para as reflexões a discussão sobre algumas prioridades, necessárias para a qualidade da educação básica no Brasil, as quais foram convertidas em cinco metas, que passaram então a ser um norteador para a elaboração do Plano de Metas no contexto brasileiro, a saber: Meta 1 - toda criança e jovem de 4 a 17 anos na escola até o ano de 2022; Meta 2 - toda criança plenamente alfabetizada até os 8 anos, até 2010: $80 \%$ ou mais, e até 2022, 100\%; Meta 3 - todo aluno com aprendizado adequado ao seu ano até 2022, 70\%; Meta 4 - todo jovem de 19 anos com o Ensino Médio concluído até 2022, 95\%; Meta 5 - até 2010, mantendo-se até 2022, o investimento público em educação Básica obrigatória deverá ser de 5\% ou mais do Produto Interno Bruto (PIB).

Pode-se afirmar ainda que na segunda etapa do movimento, o "Todos" é representado por organismos ligados ao grande capital (Banco Mundial, Organização para a Cooperação e Desenvolvimento Econômico/OCDE, Fundação Ford, Open Society Foundation) e por entidades empresariais nacionais (Confederação Nacional da Indústria, a Confederação Nacional da Agricultura, a Associação Brasileira do Agronegócio), por suas fundações e, também, pelas coalizões empresariais.

Por tal motivo, consequentemente, inaugura-se uma cultura comum que se refere à especial ênfase nas parcerias público-privadas, firmadas entre as Organizações nãogovernamentais - ONGs, que são as instituições privadas, denominadas Terceiro Setor, sem 
fins lucrativos, que têm a finalidade de gerar serviços de ordem pública (setor da sociedade), e o Primeiro Setor, que é o governo, e/ou entre o Segundo Setor, que são as empresas privadas.

Assim, em 2006 “o Todos pela Educação” se consolida como uma Organização da Sociedade Civil de Interesse Público (Oscip), com a missão de contribuir para que até 2022, ano do bicentenário da Independência do Brasil, o país assegure a todas as crianças e jovens o direito à educação básica de qualidade.

Diante destas argumentações, pode-se concluir que o Movimento não teve início vinculado a uma ação governamental, o que se justifica com dois importantes argumentos. O primeiro é que teve a sua constituição vinculada "a uma rede política que congrega agentes sociais, intelectuais, empresas, instituições públicas e privadas e grupos de interesses heterogêneos, articulados em torno de um discurso comum" (VOSS, 2011, p. 52). O segundo refere-se ao argumento relacionado à ineficiência do Estado que tem sido, segundo Souza (2006), desde os anos 1990, utilizado para justificar a necessidade da intervenção dos empresários nas questões sociais e, ao mesmo tempo, para visibilidade às 'propostas salvadoras' recomendadas pelo setor privado.

Cabe ressaltar ainda um terceiro momento para a reflexão, acerca da ideia de que a articulação da sociedade civil impulsiona no Brasil a institucionalização das ações governamentais por meio do Decreto n. 6.094, de 24 de abril de 2007, que culmina em um documento que legitima um Compromisso com a construção de políticas, cujas metas, bandeiras e atitudes do Todos Pela Educação se tornam referenciais. Paralelo a tal processo, ocorre de forma simultânea o lançamento do Plano de Desenvolvimento da Educação - PDE, que se constitui uma tentativa de assegurar a atuação governamental.

Por ser uma política pública que nasce do PDE, o "Plano de Metas Compromisso Todos pela Educação" também se constitui como um processo agregador de ações e abriga praticamente todos os programas em desenvolvimento do Ministério da Educação - MEC, com o objetivo de melhorar a qualidade da educação no país. Utiliza praticamente os mesmos pilares de sustentação do PDE, pois também se pauta em uma visão sistêmica da educação, territorialidade, desenvolvimento, regime de colaboração, responsabilização e mobilização social (BRASIL, 2015). Afinal, como dito anteriormente, tal política é um dos carros-chefes do PDE, junto ao Índice de Educação Básica - IDEB, e não poderia, portanto, partir de princípios diferenciados.

A institucionalização governamental do Programa Compromisso Todos pela Educação também se encontra respaldada na necessidade de promover a mobilização e impulsionar a sociedade para efetivar o PDE e, para tal, sistematiza várias ações na busca de uma educação

RIAEE - Revista Ibero-Americana de Estudos em Educação, Araraquara, v. 16, n. esp. 2, p. 1029-1038, maio 2021. e-ISSN: 1982-5587 
equitativa e de boa qualidade, que deverá se organizar em torno de quatro eixos: educação básica; educação superior; educação profissional e alfabetização.

Neste sentido, o Plano de Metas Compromisso Todos pela Educação estabelece um conjunto de diretrizes para que a União, os estados, o Distrito Federal e os municípios, em regime de colaboração, conjuguem esforços para superar a extrema desigualdade de oportunidades existente no Brasil.

Por tal perspectiva, a discussão sobre a organização das políticas públicas requer a compreensão de que o território em que se situa os contextos em que se concretizam ações na área da educação se constituem palco onde as políticas públicas são estruturadas com forte influência do espaço local articulada ao mundial, que segundo Amabilie (2012, p. 390) demandam,

[...] decisões que envolvem questões de ordem pública com abrangência ampla e que visam à satisfação do interesse de uma coletividade. Podendo ser também compreendidas como estratégias de atuação pública, estruturadas por meio de um processo decisório composto de variáveis complexas que impactam na realidade.

Em face dessas considerações, o dossiê Políticas e Gestão da Educação Básica em Contextos Iberoamericanos reúne artigos oriundos de estudos e pesquisas que pontuam as ações e interações das políticas e da gestão da educação básica, em suas diferentes etapas e modalidades de ensino, em contextos nacionais e internacionais.

$\mathrm{O}$ conjunto dos textos atenta-se às relações políticas macro e microcontextuais, concentrando-se em quatro eixos principais: a) estratégias, indicadores, planos e tecnologias para a educação básica; b) valorização e formação docente; c) educação do campo; e d) educação especial.

O primeiro eixo - estratégias, indicadores, planos e tecnologias para a educação básica - compreende cinco artigos.

De autoria de Èlia Lopez-Cassà, Núria Rajadell-Puiggròs e Graça dos Santos-Costa, o texto Estrategias didácticas basadas en la educación emocional como enlace entre las macropolíticas y las micropolíticas em Cataluña, depois de revisar estratégias didáticas e de educação emocional, discute as políticas na Catalunha, Espanha, relacionadas à construção de competências emocionais, tendo em vista o contexto pandêmico atual.

Em seguida, o artigo Índice de Desenvolvimento da Educação Básica (proficiência e fluxo): por que avançamos tão pouco?, de Valéria Prazeres dos Santos, Ivanei Carvalho dos Santos e Arlete Ramos dos Santos, analisa o Índice de Desenvolvimento da Educação 
Básica (IDEB) como balizador da qualidade da educação básica, relacionando-o à discussão do Plano de Ações Articuladas (PAR). As autoras sugerem análise crítica dos resultados das avaliações externas, juntamente com avaliações institucionais e envolvimento da comunidade escolar.

$\mathrm{Na}$ esteira da discussão das avalições externas, Adriene Bolzan Duarte-Antunes e Geovana Mendonça Lunardi-Mendes, com o artigo Políticas de avaliação em larga escala no contexto catarinense: em busca das traduções locais, analisam, com base na Abordagem do Ciclo de Políticas e na Teoria da Atuação de Stephen Ball e colaboradores, as traduções locais construídas pelos municípios catarinenses no âmbito da política de avaliação em larga escala. As autoras sustentam que os municípios catarinenses têm interesse na realização de avaliações em larga escala e que a transformação fica a cargo dos atores via interpretação e tradução da política.

Com o texto Plano de Ações Articuladas na gestão da educação de municípios pertencentes à Associação dos Municípios da Zona da Produção (AMZOP) - RS, de autoria de Silvana Maria Tres Cichelero, Elisiane Machado Lunardi e Carla da Luz Zinn, retomam-se as análises para o Plano de Ações Articuladas (PAR), focalizando os limites e possibilidades desse plano para a gestão da educação de municípios do estado do Rio Grande do Sul pertencentes à Associação dos Municípios da Zona da Produção (AMZOP). As autoras apontam para a necessidade de análise crítica do plano e da gestão investigada, principalmente sob o prisma da democracia e dos princípios da autonomia, descentralização de poder e da participação da comunidade.

Elena Maria Mallmann e Daniele da Rocha Schneider, autoras de Políticas públicas, tecnologias educacionais e Recursos Educacionais Abertos (REA), partindo de premissas universalizantes - como o direito à educação, à democratização do conhecimento e à aprendizagem ao longo da vida - desenvolvem uma análise interpretativo-crítica sobre os microcontextos das políticas e práticas de formação de professores para aprimoramento da Fluência Tecnológico-Pedagógica (FTP) com Recursos Educacionais Abertos (REA).

O segundo eixo do dossiê - valorização e formação docente - é composto por quatro artigos.

Daniela Oliveira Vidal da Silva e Cláudio Pinto Nunes assinam o texto Políticas públicas como instrumento de valorização docente no Brasil, e apresentam uma série de conceitos, modelos, ciclos e análises de políticas educacionais para argumentar sobre a valorização de profissionais da educação básica. Os autores defendem que esta valorização deve ser pautada em quatro pilares: formação, remuneração, carreiras e condições de trabalho.

RIAEE - Revista Ibero-Americana de Estudos em Educação, Araraquara, v. 16, n. esp. 2, p. 1029-1038, maio 2021. e-ISSN: 1982-5587 
$\mathrm{Na}$ sequência, Grace Gotelip Cabral, autora do texto Políticas de formação de professores e suas repercussões na qualidade da educação básica no Acre: o inédito viável, analisa, em perspectiva histórica, as políticas educacionais implementadas no estado do Acre, a partir de 1962, sobretudo aquelas que tem como cerne a formação de professores. A autora revela que as políticas de formação inicial produziram efeitos nas práticas pedagógicas escolares, bem como nos índices de qualidade da educação básica.

O artigo Políticas públicas de formação de professores da educação básica: panorama das atividades extraclasse no Alto Jequitinhonha/MG, de autoria de Ednéia dos Santos Cunha Neves e Mara Lúcia Ramalho, delimitando o recorte temporal - período 20132018 - e espacial - microrregião da regional Diamantina, localizada no território do Alto Jequitinhonha, Minas Gerais - analisa as Atividades Extraclasse (AEC), enquanto estratégia de formação continuada de professores da educação básica. As autoras problematizam que, embora houvesse a participação dos professores nas formações, não há garantia de existência de reflexão sobre a ação - foco das AEC.

Por sua vez, Mariangela Lima de Almeida, Rafael Carlos Queiroz, Maria Assunção Flores e Diana Alexandra Ribeiro Pereira assinam o manuscrito A pesquisa-ação crítica no desenvolvimento de políticas de formação continuada para profissionais da educação. $O$ texto atenta-se aos processos de formação de professores articulados à uma pesquisa-ação colaborativo-crítica, sobretudo ao destacar a colaboração entre educação superior e educação básica no estado do Espírito Santo/Brasil. Por fim, os autores defendem que a formação de profissionais baseada na pesquisa-ação crítica se constitui em um princípio para o desenvolvimento de políticas de formação continuada em contextos locais.

O terceiro eixo do dossiê agrupa quatro artigos que sublinham a educação do campo.

De autoria de Rosa López Valentín, Peter Michael Rosset, Lia Pinheiro Barbosa e Carla Andreia Lobo Castro, o texto Por um modelo pedagógico para uma educação agroecológica em perspectiva camponesa e indígena: avanços, tensões e desafios no Brasil e no México, apresenta conceitos, conflitos, desafios e possibilidades para a constituição de um modelo educativo-pedagógico para a agroecologia, a partir de duas experiências educativas indígenas e camponesas de microcontextos do México e do Brasil.

O artigo Educação e contradição no campo: e as escolas públicas?, de Maria Antônia de Souza, a partir de resultados de investigação em municípios paranaenses, busca compreender as políticas educacionais em relação às escolas públicas rurais. $\mathrm{O}$ texto tece problematizações relacionadas às contradições entre as grandes propriedades, o agronegócio e 
o trabalho dos diversos povos do campo, para apontar os processos excludentes que, dentre vários efeitos, acarretam na política de fechamento de escolas públicas no meio rural.

Heloísa da Silva Borges, Carlos Augusto da Silva e Riulma Ventura Muller, com o artigo Política da Reserva de Desenvolvimento Sustentável (RDS) do Tupé, no Amazonas, e as educações no contexto amazônico, examinam os documentos de criação da RDS e suas políticas para a educação. Os resultados indicam que, embora a documentação político-normativa tenha avançado no que tange à educação formal das comunidades ribeirinhas, a comunidade investigada ainda é atendida apenas por políticas paliativas.

O texto Políticas de educação do campo no Território de Identidade Sertão Produtivo na Bahia - Brasil: apontamentos de pesquisa, das autoras Tatyanne Gomes Marques, Eugênia da Silva Pereira e Priscila Teixeira da Silva, aborda os efeitos das políticas de educação do campo em um microcontexto baiano. As discussões centralizam-se nas propostas implementadas e/ou reivindicadas por diferentes atores e atrizes que protagonizam a vida e atuação no contexto da prática.

O quarto e último eixo do dossiê trata da modalidade educação especial, reunindo cinco artigos.

O artigo Educação comum ou especial? Análise das diretrizes políticas de educação especial brasileiras, das autoras Marcia Denise Pletsch e Flávia Faissal de Souza, a partir de documentos político-normativos das três últimas décadas, discute mudanças conceituais e terminológicas no que diz respeito ao público da educação especial, bem como os apoios educacionais e a formação de professores relativos a esta modalidade de educação no Brasil.

Fabiane da Silva Ferreira, Andressa Santos Rebelo e Mônica de Carvalho Magalhães Kassar, com o texto Professores, tecnologias digitais e inclusão escolar: desafios da política de educação especial em um município brasileiro, apresentam concepções de professores sobre o uso das tecnologias digitais nas atividades pedagógicas, no contexto de inclusão escolar de alunos da educação especial, em um município brasileiro fronteiriço com a Bolívia.

O texto Análise da política de inclusão escolar em um município na perspectiva de professores, de autoria de Vivian Santos e Enicéia Gonçalves Mendes, fundamentado na Abordagem do Ciclo de Políticas, analisa o contexto de influência e o contexto da prática de um município brasileiro com vistas a oferecer subsídios para melhor equacionar a política de inclusão escolar de alunos da educação especial.

RIAEE - Revista Ibero-Americana de Estudos em Educação, Araraquara, v. 16, n. esp. 2, p. 1029-1038, maio 2021. e-ISSN: 1982-5587 
De autoria de Michele Aparecida de Sá, Kamille Vaz e Taísa Grasiela Gomes Liduenha Gonçalves, o artigo Política de Educação Especial na rede municipal de ensino de Belo Horizonte-MG analisa, com base em documentação nacional e municipal e em dados do Censo Escolar, a política de educação especial da capital mineira. As autoras destacam o número expressivo de matrículas de estudantes com deficiência intelectual e a existência de ambientes segregados de educação especial, advogando em defesa da escola pública como espaço de disseminação do conhecimento sistematizado, inclusive aos alunos da educação especial.

Por fim, o artigo (Con)Textualização da política de educação especial em um município sul-mato-grossense, de Camila da Silva Teixeira Agrelos e Washington Cesar Shoiti Nozu, busca compreender as configurações da política de educação especial no município de Maracaju. Nesse processo, os autores evidenciam influências externas, a oferta de atendimento educacional especializado e o movimento de produção textual de normativa municipal sobre a educação especial.

\section{Ao todo, o dossiê Políticas e Gestão da Educação Básica em Contextos}

Iberoamericanos agrupa 18 artigos, cujos conteúdos transitam em análises das relações macro e micropolíticas, envolvendo sujeitos, grupos de interesses e entidades que atuam nos contextos de influência, de produção do texto e da prática (MAINARDES, 2006). As análises das políticas e da gestão educacional percorreram tempos-espaços do Brasil, do México e da Espanha, concentrando-se em quatro eixos para discussão da educação básica: estratégias, indicadores, planos e tecnologias educacionais; valorização e formação docente; educação do campo; e educação especial.

Espera-se que os artigos aqui reunidos possam contribuir para compreensão das forças, das disputas e dos mecanismos em jogo para o provimento do direito à educação básica nos contextos iberoamericamos. Ainda, que inspire possibilidades outras de construções, interlocuções e movimentos de luta e de resistência em prol de uma educação de qualidade, inclusiva e socialmente referenciada.

\section{REFERÊNCIAS}

AMABILE, A. E. N. Políticas públicas. In: CASTRO, C. L. F.; GONTIJO, C. R. B.; AMABILE, A. E. N. Dicionário de Políticas Públicas. Barbacena: EDUEMG, 2012.

BALL, S. J. The micropolitics of school. Oxford: Penguin Books, 1987. 
BRASIL, Ministério da Educação. Plano de Metas Compromisso todos pela educação. Instrumento de Campo. Brasília: MEC, 2008. Disponível em: http://portal.mec.gov.br/arquivos/pdf/diagnostico.pdf. Acesso em: 12 jan. 2015.

GIDDENS, A. A. A terceira via: reflexões sobre o impasse político atual e o futuro da social democracia. 4. ed. Rio de janeiro: Record, 2001.

MAINARDES, J. Abordagem do Ciclo de Políticas: uma contribuição para a análise de políticas educacionais. Educ. Soc., Campinas, v. 27, n. 94, p. 47-69, jan./abr. 2006.

NEVES, L. M. W. (Org.). A nova pedagogia da Hegemonia: estratégias da burguesia brasileira para educar o consenso na atualidade. São Paulo: Xamã, 2005.

OLIVEIRA, B. R. A implementação de políticas educacionais no nível micro: uma análise a partir dos profissionais da escola no contexto da prática. Revista de Estudios Teóricos y Epistemológicos en Política Educativa, v. 4, p. 1-17, 2019. Disponível em: http://www.revistas2.uepg.br/index.php/retepe. Acesso em: 12 dez. 2019.

SOUZA, C. Federalismo, desenho constitucional e instituições federativas no Brasil pós1988. Revista de Sociologia Política, Curitiba, v. 24, p. 105-121, jun. 2006.

VOSS, D. M. S. O Plano de Desenvolvimento da Educação (PDE): contextos e discursos. Cadernos de Educação, Pelotas, n. 38, p. 43-67, jan./abr. 2011.

\section{Como referenciar este artigo}

SANTOS, A. R.; RAMALHO, M. L.; NOZU, W. C. S. Políticas e gestão da educação básica em contextos iberoamericanos. Revista Ibero-Americana de Estudos em Educação, Araraquara, v. 16, n. esp. 2, p. 1029-1038, maio 2021. e-ISSN: 1982-5587. DOI: https://doi.org/10.21723/riaee.v16iesp2.15113

Submissão em: $15 / 12 / 2020$

Revisões requeridas em: 28/01/2021

Aprovado em: 03/03/2021

Publicado em: 01/05/2021 